\title{
Role of Oxygen Radicals in Tourniquet-Related Ischemia-Reperfusion Injury of Human Patients *
}

\author{
H.P. Friedl ${ }^{1}$, G.O. Till ${ }^{2}$, O. Trentz ${ }^{1}$, and P.A. Ward ${ }^{2}$ \\ ${ }^{1}$ Departement Chirurgie, Klinik für Unfallchirurgie, Universitätsspital Zürich \\ ${ }^{2}$ Department of Pathology, University of Michigan Medical School, Ann Arbor
}

Summary. In the current study we evaluated effluent blood from extremities of human patients undergoing reconstructive surgical treatment which is routinely accompanied by upper extremity exsanguination and application of a tourniquet. Following tourniquet release (reperfusion), there were immediate increases in the plasma levels of xanthine oxidase activity, uric acid, and histamine. Xanthine dehydrogenase activity was not detectable. Plasma also contained products consistent with the formation of oxygen-derived free radicals, namely hemoglobin and fluorescent compounds. Our data indicate in humans that ischemia-reperfusion events are associated with the appearance of xanthine oxidase activity and it's products in the plasma effluent.

Key words: Xanthine oxidase - Tourniquet - Reperfusion injury

Oxygen radicals generated by xanthine oxidase (XO) are implicated in cell and tissue injury resulting from ischemia-reperfusion procedures in animal model systems [1]. The ability of superoxide dismutase and allopurinol to protect cells and tissues from ischemia-reperfusion injury has been taken as evidence that generation of superoxide anion by XO may be relevant to the pathogenesis of the tissue injury [2]. In a variety of human tissues, immunochemical evidence for the presence of XO in vascular endothelial cells has been elicited $[8,9]$. On the other hand, no XO has been detected

\footnotetext{
* Supported in part by grants GM-28499, GM 29507, HL 31963, GM 39397, HL-21568, and HL-33064 from the National Institutes of Health and FR 744/1 from the Deutsche Forschungsgemeinschaft
}

Abbreviations: $\mathrm{XO}=$ xanthine oxidase; $\mathrm{XD}=$ xanthine dehydrogenase; IPSI=ipsilateral limb; CONTRA = contralateral limb in extracts of human myocardium [7]. These observations have raised questions regarding the pathophysiologic role of $\mathrm{XO}$ and its reaction products in ischemia-reperfusion injury in man. Recently we have shown that the activity of XO can be enhanced by the presence of low concentrations ( $1 \mu \mathrm{M}$ range) of histamine, both in vitro and in vivo [10]. In the studies reported here we sought to demonstrate a similar effect of histamine on XO activity after ischemia-reperfusion events in humans.

\section{Patients, Materials and Methods}

Venous blood samples were obtained from 22 adult human patients undergoing elective surgical treatment of upper extremities. Centripedal application of elastic bands were applied to the extremity to be surgically treated to remove all remaining blood, followed by tourniquet application (varying from 60 to $120 \mathrm{~min}$ ) to produce arterial compression and cessation of blood flow. At the end of this period the tourniquet was removed, restoring blood flow. Patients for study were selected at random and were treated in compliance with institutional procedures for the study of human subjects. No procedures were used that were not part of routine clinical practice for this type of surgical treatment. The mean age of the 22 patients was $54.3+8.3$ years (mean $\pm \mathrm{SEM}$ ). The mean tourniquet time was $67.8 \pm 17.4 \mathrm{~min}$. Surgical treatment included Dupuytren's contracture release, palmar tendolysis, ulnar nerve decompression, and other procedures. Tourniquet application was at a pressure approximately twice the systolic pressure sufficient to prevent bleeding in the surgical site. Reconstructive surgical procedures were performed in the absence of infection or other complicating factors. Before application and after release of the tourniquet, samples were obtained from venous effluent blood from the ipsilateral extremity (to 
which the tourniquet was applied) and from the contralateral extremity. No blood transfusions were used in treatment of patients. On the basis of clinical judgement, general or regional anesthesia was administered to these patients.

\section{Sample Preparation and Storage}

Using heparin-locked intravenous catheters, sequential venous blood samples were drawn from antecubital veins 10 min before placement of tourniquet and immediately after (within $20 \mathrm{~s}$ ) as well as $3,5,10,20,30,60$, and $120 \mathrm{~min}$ after tourniquet release. Blood samples $(2.5 \mathrm{ml})$ were obtained simultaneously from the ipsilateral (tourniquettreated) and contralateral arms and were collected into tubes containing $10 \mathrm{mM}$ EDTA. Each sample was diluted immediately $1: 1(\mathrm{v} / \mathrm{v})$ with ice-cold medium consisting of $2.4 \mathrm{mM}$ potassium phosphate, $150 \mathrm{mM}$ sodium chloride, $10 \mathrm{mM}$ dithiothreitol (DTT), and $1 \mathrm{mM}$ phenylmethyl sulfonyl fluoride (PMSF) at a $\mathrm{pH}$ of 7.35. This was designed to prevent artifactual conversion of XD to XO. Plasma samples were obtained by centrifugation at $4 \mathrm{C}$ within 10 min after sample collection. All samples were stored on ice and processed within $2 \mathrm{~h}$.

\section{Xanthine Dehydrogenase/Xanthine Oxidase Activity}

$\mathrm{XD}$ and XO activities were assayed spectrophotometrically by measurement of uric acid formation at $293 \mathrm{~nm}$ in the presence and absence of NAD ${ }^{+}$ at $37^{\circ} \mathrm{C}$, as described previously [10]. In some experiments $\mathrm{O}_{2}^{-}$formation was directly measured on the basis of superoxide-inhibitable reduction of ferricytochrome c. In both systems of measurement $50 \mathrm{mM}$ xanthine was added to provide substrate for the enzyme.

\section{Histamine Radioimmunoassay}

Plasma histamine was determined by radioimmunoassay using a commercially available kit from AMAC Inc. (Westbrook, ME).

\section{Hemoglobin Determination}

Hemoglobin content in plasma samples was determined spectrophotometrically at $412 \mathrm{~nm}$. Samples were diluted 1:50 (v/v) with buffer consisting of $2.4 \mathrm{mM}$ potassium phosphate, and $150 \mathrm{mM}$ sodium chloride, $\mathrm{pH} 7.35$, before measurement.

\section{Fluorescence Products of Lipid Peroxidation}

Fluorescence products in plasma were processed according the standard procedure in a fluorescent spectrofluorimeter, using excitation and emission wave lengths of 360 and $430 \mathrm{~nm}$, respectively, as described previously [11].

\section{Uric Acid Determination}

Plasma levels of uric acid were determined spectrophotometrically at $293 \mathrm{~nm}$ and expressed as $\mathrm{mmol} / 1$ using a molar extinction coefficient of $7.59 \mathrm{~cm}^{-1}$ $\mathrm{mmol} / \mathrm{l}^{-1}$ for uric acid [12]. Proof that uric acid was measured was obtained by the addition of uricase, as described below.

\section{Statistical Analysis}

Data in various groups were expressed as mean $(x) \pm$ standard error of the mean (SEM). To determine the significance of differences in samples obtained from contralateral (control) and ipsilateral (experimental) limbs, a paired t-test was used. Statistical significance was defined as $P<0.05$.

\section{Results}

Immediately after tourniquet release (reperfusion), $\mathrm{XO}$ activity, measured by uric acid formation in the presence or absence of $\mathrm{NAD}^{+}$, rose more than fourfold in plasma from the ipsilateral limb. The peak increase occurred at $5 \mathrm{~min}$ and was followed by declining levels. In blood from the contralateral limb, only a minor increase in XO activity was observed. When XO activity was determined by its generation of superoxide anion, similar data were obtained. At no time was XD activity detactable in either limb (Fig. 1).

Since $\mathrm{XO}$ reacts with available hypoxanthine and xanthine to form uric acid, plasma samples were evaluated for uric acid content. As expected, there was a significant rise in uric acid levels in plasma from the ipsilateral limb at five minutes after reperfusion. Uric acid levels in plasma from the contralateral limb remained unchanged.

Because of recent observations that histamine significantly enhances the catalytic activity of XO [6], we speculated that the ability to detect XO in plasma of reperfused limbs might be related to the availability to histamine. A radioimmunoassay demonstrated a significant increase in the histamine content in plasma from the ipsilateral but not the contralateral limb. Peak levels of plasma histamine were observed at 5 min after reperfusion 


\section{XO-activity in plasma post tourniquet release}

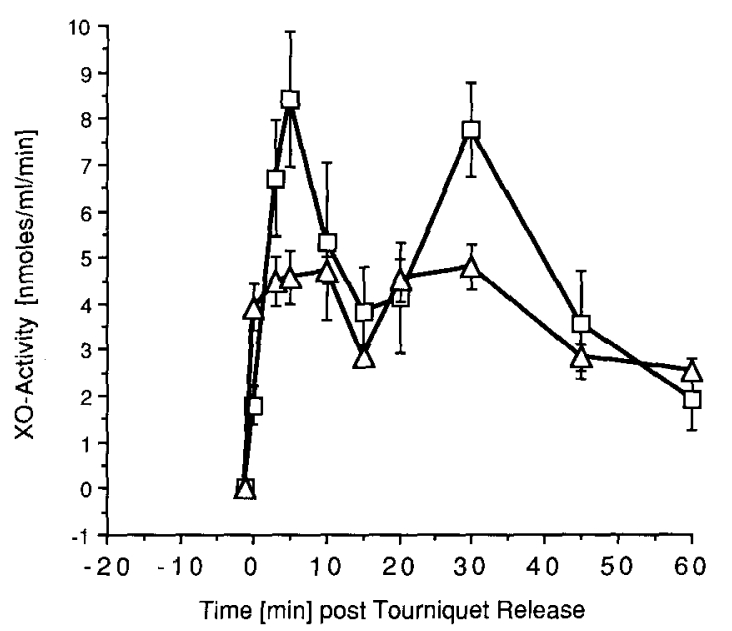

Fig. 1. Analysis of plasma from venous effluent blood of reperfused (ipsilateral) and control (contralateral) upper extremities in human patients undergoing reconstructive surgery. - - $\square-$ IPSI ; - - CONTRA

and, although declining thereafter, remained significantly elevated until $30 \mathrm{~min}$ after tourniquet release.

Furthermore, it has been shown that the intravascular generation of oxygen-derived free radicals results in damage of red blood cells with the release of hemoglobin as well as in the appearance in plasma of fluorescent compounds [13], which represent stable products of cross-linked amino-containing compounds derived from interaction with malondialdehyde [14]. There was clear evidence for the appearance of hemoglobin (with Soret bands of absorption at 412,540 , and $578 \mathrm{~nm}$ ) in plasma of the ipsilateral extremity after reperfusion, whereas in the contralateral extremity the plasma contained no such measurable material. Fluorescent products were also found in the plasma of the ipsilateral extremity after reperfusion at corresponding time points.

\section{Discussion}

These findings demonstrate for the first time that in ischemia-reperfusion events in humans, XO appears within the effluent blood of the involved tissues. The most probable source of the enzyme may be vascular endothelial cells that, having been altered by ischemia, release XO into the plasma during reoxygenation (reperfusion). Availability of substrate for XO through the breakdown of ATP may have occurred during the ischemic period, because it is now documented that cellular depletion of ATP (which would result in formation of adenine nucleotides, adenosine, inosine, hypoxanthine, and xanthine) occurs in such conditions [15]. The documented release of histamine during reperfusion could bring about enhancement of the catalytic activity of $\mathrm{XO}$, as recently demonstrated both in XO of plasma and in intact endothelial cells [10], making detection of XO possible. It is known that ischemia-reperfusion can bring about conversion within endothelial cells of XD to XO [16]. The combined results of all of these events could be endothelial cell damage, resulting in leakage of $\mathrm{XO}$ into the plasma of the reperfused extremity. With data not shown here, we have found a direct proportionality between the duration of ischemia (tourniquet application) and subsequent level of plasma XO, suggesting that the duration of ischemia and level of plasma XO may be directly linked.

\section{Conclusion}

Reperfusion of tissues after a period of ischemia is well known to result in evidence of accentuated injury [1]. It has been speculated that the injury results from the generation of toxic oxygen products, which have been produced either from tissue enzymes or from activated phagocytic cells. The ability of allopurinol and superoxide dismutase to protect tissues from ischemia-reperfusion injury has been taken as evidence that generation of superoxide anion $\left(\mathrm{O}_{2}^{-}\right)$, perhaps from xanthine oxidase $(\mathrm{XO})$, may be relevant to the pathogenesis of the tissue injury [2]. Recently, it has been suggested that generation of $\mathrm{O}_{2}^{-}$results in formation of a chemotactic factor [3] that may be responsible for the recruitment of neutrophils into the involved tissue [4]. Indeed, previous neutrophil depletion of animals undergoing ischemia-reperfusion attenuates ischemia-reperfusion injury in the myocardium and small bowel $[5,6]$.

Although bovine and rat pulmonary artery endothelial cells contain xanthine oxidase, which during ischemia is increased due to the conversion of xanthine dehydrogenase (XD), catalytically active $\mathrm{XO}$ has not been detected in extracts of human myocardium [7], even though it has been shown that in a variety of human tissues there is immunochemical evidence for the presence of $\mathrm{XO}$ in vascular endothelial cells $[8,9]$. These observations have raised questions regarding the role of $\mathrm{XO}$ and its reaction products in ischemia-reperfusion events in humans.

Addressing these questions we evaluated effluent blood from extremities of human patients 
undergoing reconstructive surgical treatment, which is routinely accompanied by upper-extremity exsanguination and application of a tourniquet, resulting in total interruption of arterial blood flow to one upper extremity. After tourniquet release (reperfusion), there were immediate increases in the plasma levels of xanthine oxidase activity, uric acid, and histamine in the ipsilateral limb and much smaller increases, if any, in levels of the same materials in plasma obtained from the contralateral extremity. There was no detectable xanthine dehydrogenase activity in plasma from either limb. Plasma also contained evidence of products consistent with the formation of oxygen-derived free radicals, namely, the appearance pre-dominantly in the reperfused limb of hemoglobin and fluorescent compounds. These data indicate for the first time in humans that ischemia-reperfusion events are associated with the appearance of xanthine oxidase activity and its products in the plasma effluent.

\section{References}

1. Granger ND (1988) Role of xanthine oxidase and granulocytes in ischemia-reperfusion injury. Am J Physiol 255:H1269-H1275

2. Granger ND, Rutili G, McCord JM (1981) Superoxide radicals in feline intestinal ischemia. Gastroenterology $81: 22-29$

3. Petrone WF, English DK, Wong K, McCord JM (1980) Free radicals and inflammation: The superoxide-dependent activation of a neutrophil chemotactic tactor in plasma. Proc Natl Acad Sci USA 77:1159-1163

4. Grisham MB, Hernandez LA, Granger DN (1986) Xanthine oxidase and neutrophil infiltration in intestinal ischemia. Am J Physiol 251:G456-G574

5. Romson JL, Hook BG, Kunkel SL, Abrams GD, Schork MA, Lucchesi BR (1983) Reduction of the extent of ischemic myocardial injury by neutrophil depletion in dogs. Circulation 67:1016-1023

6. Hernandez LA, Grisham MB, Twohig B, Arfors KE, Harlan JM, Granger DN (1987) Role of neutrophils in ischemiareperfusion induced microvascular injury. Am J Physiol 253:H699-H703

7. Eddy LJ, Stewart JR, Jones HP, Engerson TD, McCord JM, Downey JM (1987) Free radical-producing enzyme, xanthine oxidase, is undetectable in human hearts. Am J Physiol 253:H709-H711

8. Bailey IA, Blackwell CP, Woodward B (1988) Chemiluminescence measurements of xanthine oxidase and xanthine dehydrogenase activity in four types of cardiovascular cell. Basic Res Cardiol 83:392-400

9. Jarasch ED, Bruder G, Heid HW (1986) Significance of xanthine oxidase in capillary endothelial cells. Acta Physiol Scand [Suppl] 548:39-46

10. Friedl HP, Till GO, Trentz O, Ward PA (1989) Roles of histamine, complement, and xanthine oxidase in thermal injury of skin. Am J Pathol 135:203-217

11. Ward PA, Till GO, Hatherill JR, Annesley TM, Kunkel $R$ (1985) Systemic complement activation, lung injury, and products of lipid peroxidation. J Clin Invest 70:517-527

12. Waud WR, Rajagopalan KV (1976) The mechanism of conversion of conversion of rat liver xanthine dehydrogenase from $\mathrm{NAD}^{+}$-depdent form (type $\mathrm{D}$ ) to an $\mathrm{O}_{2}$-dependent form (type 0). Arch Biochem Biophys 172:365-379

13. Hatherill JR, Till GO, Bruner LH, Ward PA (1986) Thermal injury, intravascular hemolysis, and toxic oxygen products. J Clin Invest 78:629-636

14. Dillard CJ, Tappel AL (1973) Fluorescent products have reaction of peroxidizing polyunsaturated fatty acids with phosphatide ethanolamine and phenylalanine. Lipids 8:183-189

15. Achterberg PW, Nieukoop AS, Schoutsen B, de Jong JW (1988) Different ATP-catabolism in reperfused adult and newborn rat hearts. Am J Physiol 254: H1091-H1098

16. Zweier JL, Kuppusamy P, Lutty GA (1988) Measurement of endothelial cell free radical formation: evidence for a central mechanism of free radical injury in postischemic tissues. Proc Natl Acad Sci USA 85:4046-4050

17. Weiss SJ (1982) Neutrophil-mediated methemoglobin formation in the erythrocyte: The role of superoxide anion and hydrogen peroxide. J Biol Chem 257:2947-2953

18. Fantone JC, Ward PA (1982) Role of oxygen-derived free radicals and metabolites in leukocyte-dependent inflammatory reactions. Am J Pathol 197:395-418

19. Pickering R.J, Wolfson MR, Good RA, Gewurz H (1969) Passive hemolysis by serum and cobra venom factor A new mechanism inducing membrane damage by complement. Proc Natl Acad Sci USA 62:521-527

20. Vogt W, von Zabern I, Hesse D, Nolte R, Haller Y (1987) Generation of an activated form of human C5 (C5b-1ike C5) by oxygen radicals. Immunol Lett 14:209-215

Dr. H.P. Friedl

Klinik für Unfallchirurgie

Universitätsspital Zürich

Rämistrasse 100

CH-8091 Zürich, Schweiz 